This is the author's accepted manuscript of the following article: Rugo, D. (2013), "Truth after cinema: The explosion of facts in the documentary films of Jia Zhangke", Asian Cinema, 24(2), which has been published in final form at http://www.intellectbooks.co.uk/journals/view-Article,id=16761/

\title{
Truth after cinema. The explosion of facts in the documentary films of Jia Zhangke
}

Daniele RUGO, Brunel University, London

\begin{abstract}
This article identifies and elaborates on two models of resistance evident in JiaZhangke's film corpus. The deployment of different cinematic strategies produces an experimental calling into question of the value of truth and of truth as value. In the films here analysed Jia moves from resistance through organic observation to a model of resistance structured around a series of fabulations. If the first regime addresses the truth of ideology, then the target of the second is the ideology of truth. It is in this passage that Jia enters political cinema, collapsing the distinction between factual and fictional and opening up a space that belongs to no collectivity.
\end{abstract}

\section{Keywords}

JiaZhangke

documentary

I Wish I Knew

Useless

truth

resistance

Badiou

Deleuze 
Jia Zhangke's work affirms in the strongest terms cinema as art, inasmuch as his films attempt a cinematization of truth, an experimental calling into question of the value of truth and of truth as value. The context of such a gesture can be assessed through the identification of a shift between two cinematic modes of resistance. The present work elaborates on these two models. Jia moves from what could be named resistance through organic observation to a model of resistance structured around a series of fabulations. If the first regime addresses resistance against the truth of ideology, then the target of the second is the ideology of truth. The films here analysed replace truth as coherence with truth as stratification, 'the piling up of different registers of sense' (Badiou 2010: 38).

In Jia's work this change of perspective follows from the observation that in order to rival the ideal of the true it is not enough to force factual ghosts into the thin membrane of fiction. It is instead necessary to impose radical forces onto the skeleton of facts. The factual films of Jia Zhangke attempt to show that 'the ideal of the true is the most profound fiction' (Deleuze 2005: 144). Fiction is established as the creative power of facts or, better said, the false is affirmed as the creative power of truth, not so that one prevails over the other, but so that a distinction becomes impossible.

Jia's cinematic gesture could therefore be seen as a Nietzschean project aimed at confirming cinema's status as art, not because of the intrinsic aesthetic virtue of his films, but because cinema is called to rival the 'ideal of truth'. It is so that Jia fulfils F. Nietzsche's hope: 'we have art so not to die of truth' (1968: 435). 


\section{Interrupting fictional systems}

The first type of resistance - resistance through observation - addresses an explicit criticism to fictional realism, which it tries to undermine by sliding heterogeneous elements into the veracity of the filmed events. The truthfulness of fictional films is always established according to a force of exclusion. Once the flow of this force is obstructed and its coherence infringed, then the filmed event opens up to a variety of disturbances and confusions. The fictional system, self-enclosed and absolutely meaningful, shows to be permeable and convertible into its opposite, openness and dispersion of meaning. This strategy is well known to those film-makers who signal the option of modernism for cinema, either by exploring various processes of mise en abyme or by making cinema pass through Brechtian distanciation.

Jia's fundamental device is not the circular discourse on film-making, but the reversal of the gaze. The possibility to poke holes in the fictional system rests on the filmed subject's response to the enquiring gaze of the filming subject. Factual elements or better called in this case, foreign elements - resist the seduction of a seamlessly real fiction. The principle of exclusion is contaminated by a principle of reciprocation in the form 'you cannot see without being seen', 'you cannot reveal the world without the world also bearing witness to your presence'.

This preoccupation is already central to Jia as a young film-maker, starting with the short film Xiao Shan hui_jia/Xiao Shan Goes Home (1995), which 'uncovers an everyday China that has never been depicted onscreen, while humorously mocking the officious tone of both Chinese media broadcasts and high literature' (Lee 2003). As P. McGrath outlines, this question helps contextualizing Jia's trajectory within the history of 
Chinese cinema, from the reaction to socialist realism to the birth of what McGrath calls 'postsocialist realism' (2007: 85). Socialist realism - first in its Soviet and then in its Maoist version of 'revolutionary realism' - demands a scrutiny of real settings and the minute description of social conditions in order to amplify the emancipatory role of ideology. Social conditions are dictated by a specific worldv-iew. This world-view permeates the real and generates truth, the inexorable accomplishment of the Communist State. As Lin writes, 'the Sixth Generation's "subversion" is not only anti-institutional, but, more important, it is anti-ideological [...], the Sixth Generation filmmakers subverted the official artistic ideology of Socialist Realism' (2010: 8).

The reversal produced by Jia and other Chinese film-makers in the first half of the 1990s operates towards dissipation: it is enough to show the real in order to demonstrate its radical dissociation from ideology. The exhibition of life conditions stripped from ideological representations exposes official ideology as caught up in an ever-growing latency. The observation of raw reality shows that the established truth is in fact either displaced or simply false. Underneath reality, one does not find confirmation of ideological truths, but truth as an imposed and contingent construct. It is on these grounds that Jia says 'I have always regarded the independent film movement as my first lesson on democracy' (2010). In his early works Jia already starts delineating the main gesture of his art: to approach truth means to increase the problematizations of its conditions. Films should not directly oppose ideology, but subtly punctuate and therefore fragment the solidity of acquired world-views, since 'social contradictions are apparent in everyday life, but elided in representation' (McGrath 2007: 85). 
Formally, Jia concentrates his efforts on raw observations of reality, in an attempt to eliminate or limit interpretation and produce his own vision of 'a ruinous post-Mao China' (Lin 2010: 147). This intention is revealed as Jia's desire to make visible those figures and social situations that mainstream cinema left out: 'part of the reason I started making films was to respond to cinema's blind spots, its silences, on the kind of life I knew' (Chan 2009). The camera moves into the streets and becomes a public object. The audience responds to the public presence of the camera by staring back. Such a strategy invites an immediate reflection: every fiction has to remind itself that its adherence to and mimesis of the real is a technique and not a natural disposition. Fiction is limited on every side, internally and externally, by the emergence of the factual. While fiction can never quite become a fact, facts keep it under constant scrutiny.

Following G. Deleuze's classification, one can see how in Jia's three early feature films - Xiao Wu (1997), Zhàntái/Platform (2000), Rèn xiao yáo/Unknown Pleasures (2002) - an organic description coexists with a crystalline narration. In Deleuze's terms, the organic description is one in which the settings are independent from the camera, they are accepted as existing beyond the power of the camera. As Deleuze writes: 'It is not a matter of knowing if the object is really independent, it is not a matter of knowing if these are exteriors or scenery $[\ldots]$ the setting described is presented as independent of the description which the camera gives of it' (2005: 122). The outside imposes its physical laws everywhere; it resists even the dismembering of montage and commands the film to an action - situation - action model. 
The many passersby staring back at the camera still serve an organic description. In breaking up the fiction they allow for a constant identification of what is real (in this case the real is the fiction of the film, the story of the pickpocket) and what is imaginary (in this case the real passersby looking back at the camera). The imaginary comes to disrupt the continuity of the real, but the operation can always be detected as one not belonging entirely to the film. A distinction between the real and the imaginary is still possible, even if at this point the two are twisted, so that the actors and their actions are real, while the passersby from Fenyang are fictional.

However, in these films the narration is already of the crystalline type. According to Deleuze the organic narration is organized around an economic principle: characters will take the most adequate route from $\mathrm{A}$ to $\mathrm{B}$, the dialogue will be functional to the progress of the plot, the physical space will be treated according to continuity. The plot makes a claim to truth, even when it is completely fictional. As Deleuze puts it 'this is a truthful narration in the sense that it claims to be true, even in fiction' (2005: 123). What results from an organic narration is essentially a cinema of action. It is evident that even in his early films, Jia abandons this kind of narration in favour of a 'cinema of the seer and no longer of the agent' (Deleuze 2005: 123). The crystalline narration privileges characters that do not act; they rather explore or discover the environment and get lost in the plot. In Xiao $W u$ for example, the character is constructed not through his own actions, but according to the resonance of his emotional engagement with others. As Michael Berry says in his study of the Hometown Trilogy, 'the construction of Xiao Wu's identity is contingent upon those around him and when those relationships fall apart, he is left with nothing' (2009: 39). In return, the plot is constantly affected by a lack; it 
undergoes sudden falls and proceeds by unnecessary twists, which produce a 'waste of time' effect. The plot often abandons its core movement to follow marginal currents, picking something up along the way and dropping what initially seemed essential. One can say that the narration constantly strays away from its promises. Xiao $W u$ presents a plot constructed of minimal events. What is essential to its development, the police's crackdown on thieves, is always referenced as external or tangential to what is made visible on the screen. Similarly, in Unknown Pleasures, the little room visited by the young couple seems to exist outside the narration, so that the tension therein accumulated never quite releases itself on the rest of the plot. In these films, Jia is reflecting on the consequences of inscrutable global conjunctures on local situations, and how these affect the characters impeding 'their ability to cope with changes which may be as imperceptible as the shifting trends in music and fashion over months and years' (Lee 2003).

Despite the use of crystalline narration, though, the main resource of this first model of resistance remains the establishing of reciprocation. This resource is also the very limit of this model. The correspondence between the two regimes - the filmed and the filming - at this stage still reproduces the distinction and identification between two points of view, thus allowing for the possibility to name an objective narration (the camera) and a subjective narration (the character). Precisely because this regime insists on dividing fiction and reality, it can be identified as a soft mode of resistance. The regime of truth remains substantially valid. 
One could say that in these earlier films Jia is still completing a transition. At the end of this trajectory lies the substitution of 'genetic and plastic principles that give an account of the sense and value of beliefs, interpretations and evaluations, rather than transcendental principles which are simple conditions for so-called facts' (Deleuze 2006b: 87).

\section{The explosion of facts}

The second mode - resistance through fable - reverses the operation just described. Instead of introducing factual elements into fictional systems, Jia pierces the factual image with the overflowing power of fiction. This power is necessarily falsifying, in its very abolition of the distinctions true/false, fictional/factual, subjective/objective. It is factual realism that comes under scrutiny here, in particular in its acceptance of a preestablished truth produced outside the film and sanctioned as inevitable. Jia is here confronting 'the myth of objectivity [...], the fundamental mistake of preserving an idea of truth' (Marks 2000a: 201). While Jia's filming always remains with the characters, constantly 'kindled by the given object' (Kracauer 1997: 203), 'permeable to the flow of life' (Kracauer 1997: 254), he deliberately confuses 'formative impulses' and 'realistic tendencies' (Kracauer 1997: 201), to the point where formal relationships between and within shots and sequences collaborate to the content of the films. In the formal construction of his documentaries, often Jia employs a strategy of 'silences', which plays on visual seduction and formal precision, to convey what Trinh Minh-ha calls 'resistance to the packaging of knowledge' (1992: 163). 
Jia is not simply questioning documentaries' prime attraction, their 'direct, truthful access to the real' (Nichols 2001: 25). Although they draw attention to the 'the fictions of film caught in the fictions of life' (Minh-ha 1992: 165), his films are not just a reflection on the documentary form. Jia does not attempt to replace 'an aura of detached truthfulness' with 'the honest admission of a partial but highly significant, situated but impassioned view' (Nichols 2001: 511). He rather constantly returns to his characters to exemplify how facts do not provide access to a solid truth, but rather promote the idea of truth as a series of conflicting problems. Jia's films scrutinize not only the truth of documentary and factual films, but also the very idea of truth as representation devoid of contradictions. Jia's reflection on history - at once ground against which his discourse on truth matures and surface onto which this is presented - points to series of incommensurabilities. Jia's factual films therefore do not consolidate a truth opposed to official discourse; they rather draft a method where each image and each transition 'requires retracing each of these pasts into histories that are incommensurable with each other' (Marks 2000a, 2000b: 202).

The shift can be identified primarily in three of Jia's factual films: Wú Yòng/Useless (2007), 24 City (2008) and Hai shang chuan qi/I Wish I Knew (2010). As J. Xiao puts it, in these films 'one detects a consciousness of time and memory that knocks the contemporaneity of his film off kilter' (2011). In his interview with Andrew Chan, Jia declares this attention for history to be the new focus of his cinema: 'at this point, I'm most interested in emphasizing cinema's function as memory, the way it records memory, and how it becomes a part of our historical experience' (2009). 
These three films are of particular importance also because one can witness a film-maker trying to craft for himself the freedom to film the pure optical situations emerging in moments of 'violent historical mutations' (Martin-Jones 2011: 76). In other words, they show an active reconsideration of the defining and traumatic events cinema should reflect upon. This helps advancing, rather than limiting, Deleuze's idea that shifts in cinematic practices occur once these practices actively engage on reflections about their own historicity. As David Martin-Jones writes: 'various parts of the world negotiate their own defining moments of historical rupture, their own particular versions of Deleuze's isolation of the Second World War as key point of significant change' (2011: 14). Considering the specific Chinese situation, for Jia a turn to history - historically situating one's idea of cinema and experimenting with the methods such reflections impose - takes on an immediate political significance:

our political institutions discourage us from confronting and interrogating our history, but I think that kind of work is absolutely necessary. There are three areas of modern history that I'm especially interested in: the Cultural Revolution from 1966 to 1976; 1949, when the PRC was established; and the last years of the Qing Dynasty in the early 20th century. (Chan 2009)

While Jia's stress on three specifically Chinese radical caesurae makes Deleuze's choice of World War II as defining moment 'arbitrary' (Martin-Jones 2011: 19), it nevertheless confirms the importance historical traumas play in the development of cinematographic strategies. Rather than highlighting Deleuze's reading as ahistorical, 
Jia's cinema seems to corroborate the philosopher's intuition that cinema's reflection of and on history shapes its categories and formal procedures. It is in this sense that Deleuze's problems and concepts continue to be relevant for the present discussion.

Divided in three chapters, Useless focuses on the clothing and fashion industries. The film looks at various modes of clothes manufacturing, from mass production to designer clothes, to small workshops of tailors in rural areas. Rather than employing hard-hitting observational style, the film subtly diffuses the idea of a two-speed China through the use of patient cinematography. Useless opens with a series of beautifully composed tracking shots of a factory in Guangzhou, where workers go about their daily tasks, undergoing examination by an on-site doctor and consuming their meals in the factory's cafeteria. In this first part the narration proceeds free of commentary and interviews; its progression is left to carefully constructed sequences of great visual intensity. The film then turns its attention to fashion designer Ma Ke, who describes her 'completely personal' new set of designs, called Useless (Wu Yong). The collection, composed of seemingly heavy and worn-out garments with a predominance of earthy colours and hand-woven materials, draws inspiration from the clothes worn by miners and factory workers. After Ma Ke's introduction, Jia moves to Paris Fashion Week, where the designer is staging an elaborate and evocative fashion show, in which the models, faces covered with mud, stand on lightboxes in a darkened space. The final part of the triptych takes place in the mining town of Fenyang, in the Shanxi province, Jia's hometown and stage of his first three feature films. The camera follows the activities of a small workshop, where a seamstress is repairing a pair of trousers for a middle-aged man, 
before engaging in an argument with her husband over his excessive drinking. Leaving the workshop behind, Jia converses with a married couple employed in the local mine about their choice of clothes. Before the epilogue, a short interlude shows miners posing for the camera and taking a shower after a day of work. The film ends with a local tailor, whose workshop will be demolished to make way for a residential development. If the first two tableaux described mass production and haute couture, in this third episode one bears witness to those who regard clothing as little more than a necessity.

Shot in Chengdu, 24 City follows three generations of characters (in the 1950s, the 1970s and the present day) as Factory 420, once a top-secret manufacturer of military aviation parts, is transformed into an office, residential and entertainment complex for China's nouveaux riches. Jia approaches the recurrent concern about the changing landscape of China, by asking the question, which Alain Badiou identifies as central for Chinese cinema nowadays, 'what is about to happen to our factories and to our workers?' (2010: 23). Jia highlights the 'unsettling, surreal effect' (Chan 2009) of the extraordinarily rapid change China has undergone in the last fifteen years.

24 City opens with long observational shots of work in the factory until the mass gathering for the Ceremony of the Transfer of the Land. The first worker - He Xikun illustrates various stages of work in the factory and praises the attitude of an exemplary worker, whom he later visits at his home. Through the words of Guang Fengjiu, Head of Security, Jia starts explaining the strategic role that Factory 420 played in the development of Chinese military industry. Hou Lijun is then the first character to talk about the consequences of the closure of the factory for the families of those once 
employed there. At this point the transition is accomplished through the intervention of actress Lu Liping, who walks from her house to a hospital carrying an IV bag holder. Lu Liping plays a composite character, drawn from the 130 interviews that Jia recorded with workers of Factory 420. From this moment on, actors delivering lines recorded with real characters intertwine with characters that speak about their own experiences in the factory. One could say that the actors (beside Lu Liping, the cast includes Joan Chen, Chen Jianbin and Zhao Tao) speak on behalf of, they are 'intercessors' (Marks, 2000b: 203). It is Zhao Tao - a regular figure in Jia's films - that delivers the epilogue to the film. She speaks on behalf of a personal shopper, whose mother worked for Factory 420 . Her dream is to earn enough money to buy her family an apartment in 24 City.

I Wish I Knew focuses on the recent history of Shanghai. Produced in view of the 2010 World Expo, the film traverses the historical sweeps that have marked China's largest city. The conceptual framework of the film seems to sustain itself on two decisive turning points: the events of 27 May 1949, when the People's Liberation Army took control of the city and the Cultural Revolution. The film opens precisely with an account of the Cultural Revolution by painter Chen Danqing, somehow confirming Slavoj Zizek's reading that Jia provides in his films the most interesting insights on the links between the Cultural Revolution and the ongoing capitalist revolution (2009: 133). In the course of eighteen interviews, Jia delves into the complex historical web that is Shanghai, moving through the traces of western colonialism and the cosmopolitan culture of the 1930s and 1940s, analysing the consequences of the Cultural Revolution and offering glimpses of how the city has now become the roaring centre of China's financial might. 
The interviews are intertwined with archive footage shot by Jia himself (boats on the Huangpu River), staged sequences (dockers loading and unloading boats to signal the opening of Shanghai's port to foreign traders in 1842) and a number of clips taken from feature films (the propaganda film To Liberate Shanghai; Huang Baomei by Xie Jin, Flowers of Shanghai by Hou Hsiao-hsien and Days of Being Wild by Wong Kar-wai). These fictional fragments are shown to contribute to the story-telling as much as the accounts given by the characters. Jia seems to adhere to the promise of cinephilia as articulated by Serge Daney: 'not simply a particular relationship with cinema, rather a relation with the world through cinema' (2001: 23). The film is then punctuated from beginning to end by the ghostly apparitions of Zhao Tao, who drifts around the city, wearing the colour of mourning, in search of something she does not seem to find.

These films trigger a resistance to the diktat that wants facts to be treated as truths. In this second model of resistance the filmed events aim to escape the two options that they are normally relinquished to:

1. That a film must reconcile itself with an external truth by becoming adequate to it, which means that it has to consider its characters as real and truthful, according to an internal model if it is a fictional film and according to an external one when it is factual.

2. That a film must inevitably inhabit an absolutely fictional realm, even when it is a documentary, and that it cannot therefore produce reality, facts or truths, but simply play with signs. 
Jia efforts in these three factual films - which from a thematic point of view present more than one similarity with the three fictional films already analysed - are directed at affirming a particular relation of cinema with truth. This relationship on the one hand affirms the powers of cinema and on the other contests the value of acquired truths concerning the current developments of Chinese society. On the one hand therefore Jia confirms Minh-ha's claim that 'truth can only be approached indirectly, if one does not want to lose it and find oneself hanging on to a dead, empty skin' (1999: 219); on the other he affirms cinema as a specific truth-procedure.

Instances of this strategy form the very structure of Useless, 24 City and I Wish I Knew. One can therefore extract a number of passages and procedures inside the films that point to the same conclusions. In Useless, a specific case is found at the point where fashion designer Ma Ke is travelling in her car towards the countryside. Speaking to a camera installed inside the car, she talks of the tranquillity and serenity of little villages and of the restoring effects of the countryside, where it is possible to establish a more balanced relationship to one's surroundings. Just before Ma Ke approaches a bend in the road, the camera suddenly moves outside the car, leaving this to disappear in the background and revealing a middle age man holding a plastic bag. The man then starts walking on a muddy road, until he reaches a small workshop in Fenyang, where a woman fixes his worn out trousers for a modest price. This movement signals the beginning of the third part of the film. This transition is of particular interest since it presents a multifaceted interlacing of fictional and factual, where it is impossible to fix them on two opposite poles. Ma $\mathrm{Ke}$ is an internationally appreciated designer, whose clothes are exhibited in sophisticated performances in Paris. The inspiration for the designs on 
display in Paris (which the models find awkward and uneasy to put on) comes from the clothes worn by miners and workers in their everyday life. The middle age man at the border of the road is precisely one of those workers whose daily activities inform Ma Ke's collection.

A fictional device - a man placed on the border of the road - is used to introduce a series of characters whose reality is the source of a fiction that has in turn produced another reality (in Paris). The document puts the fiction into perspective, only through the reminder that a link between the two can only be established by crafting another fiction.

It is not just in the passage from one episode to another that Jia inserts falsifying devices. This same situation can be seen at work within single sequences, individual accounts and characters. 24 City is exemplary here because entirely balanced on the ambiguous status of the ones who speak and therefore of the value of their discourses. What Jia is after here is the collective foundation of memory and it is this that 'finally renders performed storytelling as meaningful as real reminiscences' (Xiao 2011). As S. Wu notices, 'all characters, real and fictional, are framed in medium shots in realistic settings [...], arranged in a sitting position slightly tilting to the right or the left of the frame and facing gently sideways' (2011: 8).

The ambiguity rests not simply on the awareness that the one who articulates a discourse on the factory could be at any point an actor delivering the line of an unnamed worker or a worker acting a particular narrative role. The ambiguity is embedded in each and every discourse, regardless of the agent delivering it. In other words, what a character is saying could be true, but this truth always introduces and activates the moment that 
displaces it or exposes it as partial. Every account immediately makes room for its own contradiction. The taking over of the factory is presented, at once, as the erasure of the past, the promise of the new, the return of the past. The very physical space of the factory undergoes this same oscillation: it can be presented at once as a place of production and as hollow scenery. The factory as 'Factory 420 ' is presented both with workers carrying out their duties and as an empty and decaying container. The factory as '24 City' is also shown as a site under construction (the labour of the future?) and as an aseptic white cube. The two levels are constantly negotiating their actuality.

The closing lines, delivered by Zhao Tao, seem then to frame the entire film in this direction. She convincingly negates her past through her actions. There is no trace of Communist utopia in her bright BMW Beetle and even less in the description of her job as personal shopper. The character speaks from a society completely converted to consumerism and that already displays the distinctive fatigue proper of consumerism. At the same time though she produces an extraordinary reaffirmation of the past, precisely when the time comes to reveal her plans for the future. One is led to discover that it is precisely the redemption of the past that motivates her appetite for wealth. The two formulations - the past is only past and the past is the truth of the future - are presented as being equally true.

It is I Wish I Knew that brings the resources of this second mode of resistance to their strongest amplification. Here it is the history of the city itself that is produced according to a falsifying narration. This procedure can be seen at work on many levels, all composed within themselves of strata of differentiation, which ultimately put history 
into contact with what cannot be yet thought: 'the silent plurality of senses of each event' (Deleuze 2006b: 4). This method, rather than being 'self-defeating' (Xiao 2011), allows Jia to present the entirety of history as a field from which to draw complications and diverging storylines. As Andrew and Xu write, Jia 'has attempted to record this city's slipping presence, Shanghai's "today," which is becoming "yesterday," and then falling into a more and more distant "past"” (2011: 25).

The accounts provided by the characters are often intertwined with footage from films, suggesting that the history described in this particular film is also one created by cinematographic fictions. This device transmits the idea that the history of Shanghai is not simply being read by the director; rather the film collaborates to its creation. The history of Shanghai is not just the matter of the film, but also its product and fiction. Throughout the film the city is presented as 'one huge construction site' (Andrew and $\mathrm{Xu}$ 2011: 26). The history of Shanghai must be traced in the story of the film and not the other way around.

These two levels - history and story - are mixed to the point of blurring any distinction. Zhu Qiansheng, production manager on Michelangelo Antonioni's Chung Kuo - Cina (1972) has been condemned during the Cultural Revolution for allowing the Italian director to see too much reality, thus for contributing to a fiction around China, rather than to the description of its reality. Antonioni's demand to see the real has produced a fiction opposed to the official fiction, the fiction of the Party. The punishment the character had to submit to is itself part of a spectacle and a modus operandi of the official fiction. Jia highlights this seamless passage from fiction to factual by shooting in the same teahouse as Antonioni and cutting between his own and Antonioni's footage. 
Even more explicit is the case of Wang Peimin, daughter of Wang Xiaohe, arrested and put to death in Tilanqiao Prison by the Guomindang, days before she was born. She appears at Chedun Film Studio, on the set at of a movie staged during the war between the Maoist army and Chiang Kai-shek's. The set provides a reconstruction of Shanghai's Nanjing Road from the time and Jia catches a glimpse of the shooting with a group of soldiers marching through the city. Wang Peimin is part of the history underlying the fiction in production, but she also becomes, in I Wish I Knew, part of that very fiction.

Instances of this type, where reality and fiction are conflated, recur throughout the film, with the two extreme poles formed by Zhao Tao's wondrous appearances (a purely fictional element) and the deeds of model worker Huang Baomei (a purely factual element) fixed in time thanks to Xie Jin's biopic.

The point, then, is not that one must resort to fiction in order to speak of the real, but that the two cannot be clearly distinguished. Under the pressure of these continuous negotiations, movement becomes essentially false.

At this point it is possible to see how Jia has completed the transition described in the discussion of his early feature films. The crystalline narration completely takes over the image and therefore converts the organic description into a crystalline one. In the regime of crystalline description, concrete spaces cease to be organized economically, the action enters a crisis because the space around it is completely liberated. The setting is now created by the camera, which can displace and contradict it or collapse distinctions between two different spaces. Space is not pre-determined, but purely optical, sound and 
tactile, created only through the resources of cinema. Movement is essentially false (exemplary how Jia moves from the factual to the reconstruction in I Wish I Knew). Deleuze writes: 'narration is constantly being completely modified, in each of its episode, not according to subjective variations, but as a consequence of disconnected places and de-chronologized moments'(2005: 129).

There where the model of the true and the organic regime establish identification and veracity, the multiplicity of sense investing the crystalline image points towards the false. As Deleuze remarks: 'Description stops presupposing a reality and narration stops referring to a form of the true' (2005: 130).

In the story - the third element Deleuze analyses - the distinction between subject and object blurs. Camera and character cannot be distinguished anymore, not even their identification is possible, because they do not exist as separate elements since the beginning. In this constellation, subjective points of view can simply be the margin of a vision, a mental vision or memory, completely reconstructed by the camera, by the power of the camera to imagine beyond the human eye. A character's account can become the foreword to a twist imposed on the plot by possible and virtual consequences of this account. Vice versa, the character may be called to respond to what has been imagined, but has not happened (we see it, but we know it is the filmic translation of an impossible event). What this kind of regime shows is that no point can be simply exposed as the real or the true, powers of the false show virtual images constantly animating actual ones and therefore dismantle the ground from which an assignation of truth as an ultimate value becomes possible. Deleuze offers the power of the false not simply as a principle of reflection, but one implicated in the process of production: 'the images must be produced 
in such a way that the past is not necessarily true, or that the impossible comes from the possible' (2005: 127).

Characters are shown to act in ways they deem true, but the result of this action shows truth as a higher power of falsification. I Wish I Knew completes a process thanks to which Jia performs a cinematization of truth, exposing the ideal of truth of factual films as a labour of fiction. The impossibility to claim a truth is not however treated as a deficiency; rather, in the film truth remains unconceivable, while always being conceived of. Similarly, Deleuze would argue that a truth can only be sought through increasing problematizations and cannot be separated from the procedures that establish it (Deleuze 2006a: 69). The establishing of truth progresses according to irrational breaks. As Laura Marks puts it in her description of 'time-image documentaries', these 'seek to acknowledge that the most important "events" are invisible and not visualizable' (2000b: 205). Cinematization of truth would then be the specific process through which cinema forms its own procedure of truth, by transforming the model of the true. Truth in the cinema does not proceed by exclusion and simplification of acquired knowledge. It is always formed through the elaboration of complex and problematic relations within singular accounts and the delimitation of problems across different accounts. It is not a new solid truth that is uncovered at the end of this processes, rather one faces the demand for more excavations and for more questions. As Marks puts it: 'there is a moment of suspension that occurs in these works after the official discourse has been (if only momentarily) dismantled and before the emerging discourse finds its voice' (Marks 2000b: 25). 
In Jia's films, the mystification of facts and the alteration of documents serve to demystify the truths that follow from these facts. In other words, where mystified truth is shown as natural, the underlying mystification can be exposed only by falsifying facts even more, pushing them into sequences where they cannot be distinguished from fictions. In this way Jia aims to show that the construction of truth is fabulation. Defined by H. Bergson as the production of 'phantasmatic representations' (1977: 97), fabulation is deemed a 'virtual instinct' (Bergson 1977: 100). In adopting and adapting this expression, Deleuze makes it the cornerstone of the encounter between art and politics. Fabulation substitutes utopia in describing the invention of a people: 'when a people is created, it does so through its own means, but in a way that rejoins art... or in such a way that art rejoins that which it lacks' (Deleuze 1995: 174). There where Bergson writes 'nothing can resist facts' (Bergson 1977: 109), Deleuze inverts the formula: it is the invention of facts that triggers and structures various forms of resistance. As Marks puts it, documentaries can 'mobilize the stories of these opinionated tellers against official versions of history in absurd or poignant pairings' (2000b: 203). In mobilizing pasts that are incommensurable to each other, Jia speaks therefore the truth of a 'missing people', missing in between inevitable truths: the truth of the inevitable progression from Communism to Capitalism and that of the progression from Capitalism to happiness. In Jia's words, the emphasis moves from 'Challenge Authority in the Past' to 'Challenge the Market in the Present' (2010).

There is neither truth nor appearance, but power of the false, power to enter into series of fabulations: facts becoming truth, truth becoming fabulation, fabulation 
becoming facts and so on. Every truth is a multiplicity of fictions that in turn propel a multiplicity of truths.

\section{The task of the document}

This second mode of resistance shows that in order to rival the ideal of truth it is not enough to let facts interrupt fictions; one has to learn how to show the fictional nature of facts. Under this mode of resistance, Jia seems to outline the task of factual filmmaking. One can therefore extract a number of conclusions:

- fiction is not opposed to the real; what is at stake is rather the appropriation of the profound fiction at the heart of the real

- this appropriation forces a cinematization of truth; the film imposes its own truth by articulating the labour of fiction stolen from the real. The film begins by affirming that the labour of fiction belongs to facts

- the character enters the real in making up stories, showing that the real and its accepted truth, work precisely in this way: fabulation.

The task of cinema would then be twofold: on the one side to make so that cinema - despite the specificity of the plot, the characters, their dialogues and actions - becomes real out of fiction; on the other to show that the real can at any moment pass into a series of fictions, from which it cannot be distinguished. This task offers the production and agitation of a specific thought: to make truth pass through the ability of cinema to present both the virtual and the actual, so that truth remains entangled 'in the infinity of the real' (Badiou 2010: 38). 
It is in this passage from the unveiling of the truth constructed by ideology to the exposure of truth as ideology, that Jia enters political cinema. To expose the fictional moment at the heart of the real, collapsing the distinction between factual and fictional, means to open a space that belongs to no collectivity. The collectivity Jia's films address their message to does not yet exist, it is the task of these films - their thought, their measure and their truth - to create it.

\section{References}

Andrew, D. and Xu, J. (2011), 'The lion's gaze: Truth and legend in I Wish I Knew', Film Criticism, 36:1, pp. 24-43.

Antonioni, Michelangelo (1972), Chung Кио - Cina, Rome: RAI.

Badiou, A. (2010), Cinéma, Paris: Nova Éditions.

Bergson, H. (1977), The Two Sources of Morality and Religion (trans. Ashley Audra and Cloudseley Brereton), Westport, CT: Greenwood Press.

Berry, C. (2008), 'Xiao Wu: Watching time go by', in C. Berry (ed.), Chinese Film in Focus II, London: British Film Institute, pp. 120-45.

(2009), 'Jia Zhangke and the temporality of postsocialist Chinese cinema: In the now (and then)', in O. Khoo and S. Metzger (eds), Futures of Chinese Cinema: 
Technologies and Temporalities in Chinese Screen Cultures, Bristol: Intellect Book, pp. $111-28$.

Berry, M. (2009), Xiao Wu, Platform, Unknown Pleasures, Jia Zhangke's 'Hometown Trilogy', London: British Film Institute.

Chan, A. (2009), 'Jia Zhangke interview', film comment', March/April, http://www.filmlinc.com/film-comment/article/jia-zhangke-interview. Accessed 10 March 2012.

Daney, S. (2001), La Maison Cinéma et le Monde. Tome 1. Les Temps des Cahiers 19621981, Paris: P.O.L.

Deleuze, G. (1995), Negotiations (trans. Martin Joughin), New York: Columbia University Press.

(2005), Cinema 2: The Time-Image (trans. Hugh Tomlinson and Robert Galeta), London: Continuum. (2006a), Foucault (trans. Seán Hand), London: Continuum. (2006b), Nietzsche and Philosophy (trans. Hugh Tomlinson), London: Continuum. 
Krakauer, S. (1997), Theory of Film: The Redemption of Physical Reality, Princeton, NJ: Princeton University Press.

Lee, K. (2003), 'Jia Zhangke', Senses of Cinema, no. 25, March, http://www.sensesofcinema.com/2003/great-directors/jia/. Accessed 11 March 2012.

Lin, X. (2010), Children of Marx and Coca Cola. Chinese Avant-Garde Art and Independent Cinema, Honolulu: University of Hawai'i Press.

Marks, L. (2000a), 'Signs of the time: Deleuze, Peirce, and the documentary image', in G. Flaxman (ed.), The Brain is the Screen: Deleuze and the Philosophy of Cinema, Minneapolis: University of Minnesota Press, pp. 193-214.

(2000b), The Skin of the Film: Intercultural Cinema, Embodiment, and the Senses, Durham, NC and London: Duke University Press.

Martin-Jones, D. (2011), Deleuze and World Cinemas, London: Continuum.

McGrath, P. (2007), 'The independent cinema of Jia Zhangke. From postsocialist realism to a transnational aesthetic', in Z. Zhang (ed.), The Urban Generation: Chinese Cinema and Society at the Turn of the Twenty-First Century, Durham, NC and London: Duke University Press, pp. 81-114. 
Minh-ha, T. (1992), Framer Framed. Film Scripts and Interviews, London: Routledge. (1999), Cinema Interval, London: Routledge.

Nichols, B. (2001), Introduction to Documentary, Bloomington, IN: Indiana University Press.

Nietzsche, F. (1968), The Will to Power (trans. W.A. Kaufmann and R. J. Hollingdale), London: Vintage Books. (1979), Philosophy and Truth. Selections from Nietzsche's Notebook of the Early 1870's (trans. Daniel Breazeale), New Jersey and London: Humanities Press International.

Jia, Zhangke (1995), Xiao Shan hui_jia/Xiaoshan Goes Home, Beijing: Beijing Film Academy. (1998), Xiao Wu/Pickpocket, Beijing: Hu Tong Communications. (2000), Zhàntái/Platform, Beijing: Artcam International, Bandai Entertainment Inc., Hu Tong Communications, Office Kitano, T-Mark. 
(2002), Rèn_ xiao yáo/Unknown Pleasures, Beijing: E-Pictures, Hu Tong

Communications, Lumen Films, Office Kitano, T-Mark.

(2007), Wú Yòng/Useless, Beijing: Xstream Pictures.

(2008), 24 City, Beijing: Xstream Pictures.

(2010), Hai shang chuan qi/I Wish I Knew, Beijing: Xstream Pictures.

Jia, Z. (2010), 'Speaking of "the Sixth Generation": I don't believe that you can predict our ending', DGenerate Films website, http://dgeneratefilms.com/academia/full$\underline{\text { translation-of-jia-zhangkes-essay-on-sixth-generation-cinema-now-available/. }}$ Accessed 10 March 2012

Wu, S. (2011), 'Time, history and memory in Jia Zhangke's 24 City', Film Criticism, 36:1, pp. 3-23.

Xiao, J. (2011), 'The quest for memory: Documentary and fiction in Jia Zhangke's films', Senses of Cinema, no. 59, June, http://sensesofcinema.com/2011/featurearticles/the-quest-for-memory-documentary-and-fiction-in-jia-zhangke\%E2\%80\%99s-

films/. Accessed 20 February 2012.

Zizek, S. (2009), First as Tragedy, Then as Farce, London: Verso. 


\section{Contributor details}

Daniele Rugo lectures at Brunel University, London and is co-founder of InC Continental Philosophy Research Group. His articles have appeared in journals including the Journal of Italian Cinema and Media Studies, Film-Philosophy and Scope. He is author of Jean-Luc Nancy and the Thinking of Otherness: Philosophy and Powers of Existence (London \& New York: Bloomsbury, May 2013).

\section{Contact:}

Dr Daniele Rugo, School of Arts, Brunel University, UB8 3PH, UK.

E-mail: daniele.rugo@brunel.ac.uk 